\title{
Improving Firearm Storage Habits: Impact of Brief Office Counseling by Family Physicians
}

\author{
Teresa L. Albright, MD, and Sandra K. Burge, PhD
}

Background: Firearm injury is the leading cause of injury-related death among youth and second leading cause of injury-related death overall in the United States. Our objective is to determine the impact of brief office counseling by family physicians on patients' firearm storage habits.

Methods: Of the 1,233 patients who completed the enrollment questionnaire, 156 (13\%) reported they had guns in their household and agreed to participate in the study. Postintervention survey instruments were completed by 127 (81\%) of participants. Participants received either no counseling, verbal counseling alone, or counseling and a gun safety brochure from their physician. Firearm storage habits were measured at baseline and 60 to 90 days after intervention.

Results: At the postintervention interview, $64 \%$ of the group receiving verbal counseling and $58 \%$ of the group receiving verbal counseling plus written information made a safe change in gun storage compared with $33 \%$ of participants in the no-intervention group $(P=.02)$. A logistic regression model controlling for demographics and gun ownership showed that compared with the no-intervention group, intervention participants were three times more likely to make safe changes.

Conclusions: Family physicians' brief counseling efforts made a significant positive impact in the firearm storage habits of their patients. With a verbal or written recommendation, a significant improvement was observed in firearm storage. (J Am Board Fam Pract 2003;16:40-6.)

Firearm-related injuries are the second leading cause of injury-related death in the United States. Approximately 15,000 unintentional gunshot wounds are treated in US hospital emergency departments each year. Unintentional fatal and nonfatal firearmrelated injury rates are highest among persons aged 15 to 24 years. Firearm-related suicide rates are highest among persons older than 65 years. ${ }^{1}$

At least 25 million households have handguns, and studies report as many as $20 \%$ to $50 \%$ of handguns are stored unlocked and loaded. ${ }^{2}$ Unanticipated or easy access to loaded, unlocked firearms in the household is implicated in unintentional deaths among children and in youth suicide and homicide. Access to unlocked or loaded weapons increases the risk of injury or death. ${ }^{3-5}$

Historically, physicians have tackled many controversial health issues. They have raised patients' awareness with antismoking campaigns, child car

Submitted, revised 2 May 2002.

From the Corpus Christi Family Practice Residency Program at Christus Spohn Memorial Hospital, Corpus Christi (TLA), and the Department of Family and Community Medicine and the University of Texas Health Science Center at San Antonio (TLA, SKB). Address reprint requests to Teresa L. Albright, MD, Corpus Christi Family Practice Residency Program, 2606 Hospital Blvd, Corpus Christi, TX 78405 . seats, and safety belt laws. ${ }^{6,7}$ Currently, family physicians and pediatricians regularly address difficult and controversial issues, such as sexual habits, infection with human immunodeficiency virus, and domestic violence. Safe storage of guns is supported by the American College of Physicians, ${ }^{8}$ the American Academy of Pediatricians, ${ }^{9}$ the American Medical Society, ${ }^{10}$ the National Rifle Association, ${ }^{11}$ and the Sporting Arms and Ammunition Manufacturers Institute. ${ }^{12}$

Patients and physicians have expressed lack of confidence and conviction in the efficacy of firearm safety counseling by physicians. Whereas most patients agree that physicians can influence public opinion, ${ }^{13}$ significantly few patients actually believe physicians are knowledgeable in, or responsible for, gun safety counseling. ${ }^{14}$ Although most pediatricians feel they should counsel their patients about firearm safety, less than one half might actually do so. ${ }^{15}$ Physicians list barriers of time, being unsure what to tell patients, and believing patients would not heed advice on storage as reasons for not counseling in their practices. ${ }^{16}$

Our objective was to study the impact of brief verbal and written counseling regarding firearm storage among family practice patients in an ambulatory clinic setting. 


\section{Methods}

Investigators conducted this study in a communitybased, university-affiliated family practice residency training program located in an urban area in the southwestern United States. Program faculty and residents staff two clinics and accept both private and county-assisted patients. Institutional Review Board application was made and received before beginning this study.

\section{Intervention}

The principal investigator preselected survey days and provided appropriate study materials to physicians seeing patients on those days. Investigators assigned patients into one of three experimental groups. On each survey day, all patients enrolled into the study were assigned to the same group. Group assignment rotated every survey day.

On survey days, each physician's nurse interviewed the first 3 patients arriving for clinic appointments. These appointment slots were general adult or pediatric slots, with no regard to type of visit or complaint. After collecting basic demographic information, the nurse asked, "Does anyone living in your home own a gun?" If the patient answered "no," the interview ended. If the patient answered "yes," the nurse obtained informed consent to participate in the study, then asked the patient to complete the gun ownership questionnaire.

The gun ownership questionnaire documented demographic information and the numbers and types of firearms in patients' households, the general location of guns, and the storage methods, specifying whether the guns were stored loaded or unlocked. If children were in the household, patients reported whether the children knew the location of the guns or could gain access to the guns through knowledge of keys or lock combinations. Investigators defined triple-safe gun storage as guns stored unloaded, locked, and not accessible by children. At the follow-up interview, safe storage included reports of getting rid of the gun.

During the appointment, the physician delivered the assigned intervention or no intervention. Study packets contained survey questionnaires only (group 1 - control group), or survey questionnaires plus counseling statements (group 2 - verbal counseling group), or survey questionnaires plus counseling statements plus printed brochures (group 3 - verbal plus written counseling group). All materials were available in English and Spanish. For Spanishspeaking patients, bilingual staff and physicians provided counseling and assistance with survey questionnaires when necessary.

Group 1, the control group, was administered the enrollment and 60-day follow-up gun ownership questionnaire only; they received no firearm safety or storage information.

In addition to the enrollment questionnaire, participants in group 2 received verbal counseling. Physicians stated or read the following advice: "Having a loaded or unlocked gun in your house increases the risk of injury or death to family members, whether by accident or on purpose. I urge you to store your unloaded guns in a locked drawer or cabinet, and out of the reach of children."

Participants in group 3 received the enrollment questionnaire and verbal and written counseling. Their physicians stated the same advice as above and provided a brochure entitled "Keep Your Family Safe," produced by the American Academy of Pediatrics and the Center to Prevent Handgun Violence.

Sixty to 90 days after enrollment, investigators telephoned participants at home to administer the postintervention gun ownership questionnaire. These interviewers were given the name and telephone number for each contact, but no additional information regarding experimental group.

Investigators considered gun storage to be improved if patients reported one or more of the following safe changes: (1) unlocked guns at enrollment and locked guns at follow-up, (2) loaded guns at enrollment and unloaded guns at follow-up, (3) children had access to guns at enrollment and no access at follow-up, or (4) at follow-up, moving guns to a safer place in the last 60 days.

Investigators considered gun safety to be threatened if patients reported one or more of the following unsafe changes: (1) locked guns at enrollment and unlocked guns at follow-up, (2) unloaded guns at enrollment and loaded guns at follow-up, or (3) no child access to guns at enrollment but access at follow-up.

The follow-up survey also included a question regarding participants' comfort with answering questions about firearm safety: "Does it bother you to be asked about gun safety and storage at your doctor's office?" 
During enrollment, clinic nurses screened 1,233 adult patients (aged 18 years or older) and adults accompanying child patients for gun ownership. One hundred fifty-six (12.7\%) patients responded, "yes" and agreed to enter the study. Of the 156 enrolled, 127 patients provided complete preintervention and postintervention data. Analyses examined group differences in changes in firearm storage.

\section{Analysis}

Investigators conducted two waves of analyses. The first included only the 127 participants who completed both enrollment and postintervention survey questionnaires. The second intention-to-treat analysis used all 156 patients, classifying those lost to follow-up as no change in gun storage habits. Chisquare analysis assessed simple group differences in changes in gun storage. Logistic regression analyses examined group differences while controlling for demographic and gun ownership variables. Using safe changes and unsafe changes as dependent variables, investigators entered the following predictors in the first block: ethnic background, sex, age, number of children, number of guns, handgun ownership, and rifle or shotgun ownership. Then they entered a dichotomous intervention-no intervention variable in the second block of predictors. Finally, descriptive analyses report on participants' open-ended responses to the question, "Does it bother you to be asked about gun storage and safety at your doctor's office?"

\section{Results}

Nurses screened 1,233 patients and collected demographic information. Most patients were female (73\%) and Hispanic (76\%), with a mean age of 45.5 years. Approximately 2\% were either Spanishspeaking only or requested a questionnaire in Spanish. One hundred fifty-six (12.7\%) reported guns in their household and agreed to participate in the study. Less than $0.5 \%$ of those reporting guns in their household declined to participate. Compared with patients who did not own guns, gun owners were more likely to be male ( $32 \%$ vs $26 \%, P=$ $.052)$, non-Hispanic white ( $40 \%$ vs $15 \%, P<.001)$, and older (mean age $=49$ years vs 45 years, $P=$ .004). Among the 156 gun owners, 127 completed usable enrollment and postintervention questionnaires, for an $81 \%$ follow-up rate. We found no significant differences between those who completed the questionnaires and those who did not in terms of age, sex, ethnic background, use of Spanish language, number of children in the household, methods of gun storage (loaded or unloaded; locked or unlocked), or number of guns owned (Table 1).

\section{Sample Characteristics}

Sample characteristics appear in Table 1. Most patients who completed the study were female and Hispanic, with a mean age of 49.1 years. At enrollment, 36\% stored guns in a triple-safe way- unloaded, locked, with no access by children. Twenty percent stored guns loaded, and 51\% stored firearms in unlocked locations. Twelve percent had children who knew the location of the firearms. The mean number of guns for each household was 2.8 , and the mode was 1 gun ( $48 \%$ of sample), ranging from 1 to 25 guns. Nearly one half, $48 \%$, owned handguns, and $62 \%$ owned rifles or shotguns. The three experimental groups were similar in demographic composition and in gun storage habits, with one exception. Ethnic background differed significantly; group 2 had more Hispanics and fewer non-Hispanic whites than the other groups.

\section{Changes in Firearm Storage Among Follow-up Participants}

At enrollment, $36 \%$ of participants reported triplesafe gun storage, compared with $54 \%$ at follow-up. Fifteen participants (12\%) reported getting rid of the gun(s) between enrollment and follow-up. Examining only those 77 participants who did not report triple-safe storage at enrollment (they stored guns loaded or unlocked, or children knew the location), investigators found that $53 \%$ changed to triple-safe gun storage at follow-up. These changes differed by experimental group. More than one half of the participants in intervention groups reported triple-safe gun storage at follow-up, $63 \%$ and $59 \%$, compared with $33 \%$ of the control group. A twogroup comparison (control vs intervention groups combined) resulted in $\chi^{2}=4.60(P=.032)$.

Considering all 127 participants who completed the study, $33 \%$ of the control group made one or more safe changes in gun storage between enrollment and follow-up, compared with $64 \%$ of the counseling-only group and $58 \%$ of the counselingplus-brochure group $(P=.017)$ (Table 2). Twentyeight percent of all participants made unsafe 
Table 1. Characteristics of the Sample.

\begin{tabular}{|c|c|c|c|c|c|}
\hline Survey Results & $\begin{array}{c}\text { Patients } \\
\text { Completing } \\
\text { Project } \\
(\mathrm{n}=127) \\
\% \text { (No.) }\end{array}$ & $\begin{array}{c}\text { Group 1 } \\
\text { Control Group } \\
(\mathrm{n}=39) \\
\%(\text { No. })\end{array}$ & $\begin{array}{c}\text { Group } 2 \\
\text { Verbal Counseling } \\
(\mathrm{n}=36) \\
\%(\text { No. })\end{array}$ & $\begin{array}{c}\text { Group } 3 \\
\text { Verbal }+ \text { Written } \\
\text { Counseling } \\
(\mathrm{n}=52) \\
\% \text { (No.) }\end{array}$ & $\begin{array}{l}\text { Lost to } \\
\text { Follow-up } \\
(\mathrm{n}=29) \\
\% \text { (No.) }\end{array}$ \\
\hline \multicolumn{6}{|l|}{ Demographic characteristics } \\
\hline Male & $31(39)$ & $36(14)$ & $33(11)$ & $25(13)$ & $38(11)$ \\
\hline Female & $69(88)$ & $64(25)$ & $67(24)$ & $75(39)$ & $62(18)$ \\
\hline African American* & $6(8)$ & $8(3)$ & $3(1)$ & $6(3)$ & $10(3)$ \\
\hline Hispanic* & $55(70)$ & $39(15)$ & $81(29)$ & $50(26)$ & $45(13)$ \\
\hline White* & $39(49)$ & $54(21)$ & $17(6)$ & $44(23)$ & $45(13)$ \\
\hline Spanish only & $2(3)$ & $-0(0)$ & $3(1)$ & $4(2)$ & $3(1)$ \\
\hline Children in household & $41(52)$ & $41(16)$ & $42(15)$ & $39(20)$ & $32(9)$ \\
\hline Mean number of children & $0.7(1.2 \mathrm{SD})$ & $0.6(0.8 \mathrm{SD})$ & 0.7 (0.9 SD) & $0.9(1.5 \mathrm{SD})$ & $0.6(1.0 \mathrm{SD})$ \\
\hline Mean age, years & $49.1(14.0 \mathrm{SD})$ & $50.4(13.5 \mathrm{SD})$ & $48.1(15.6 \mathrm{SD})$ & $48.9(13.4 \mathrm{SD})$ & $47.1(15.4 \mathrm{SD})$ \\
\hline \multicolumn{6}{|l|}{$\begin{array}{l}\text { Gun storage and ownership } \\
\text { at enrollment }\end{array}$} \\
\hline Triple safe storage & $36(46)$ & $41(16)$ & $33(12)$ & $35(18)$ & $27(8)$ \\
\hline Stores gun loaded & $20(25)$ & $26(10)$ & $11(4)$ & $22(11)$ & $31(9)$ \\
\hline Stores gun unlocked & $51(65)$ & $41(16)$ & $61(22)$ & $52(27)$ & $52(15)$ \\
\hline $\begin{array}{l}\text { Children know location } \\
\text { of gun }\end{array}$ & $12(6$ of 51$)$ & $25(4$ of 16$)$ & $0(0$ of 15$)$ & $10(2$ of 20$)$ & $20(3$ of 15$)$ \\
\hline Mean number of guns & $2.8(3.6 \mathrm{SD})$ & $2.5(3.9 \mathrm{SD})$ & $3.8(4.4 \mathrm{SD})$ & $2.4(2.4 \mathrm{SD})$ & $4.6^{\dagger}(11.4 \mathrm{SD})$ \\
\hline Owns handguns & $48(61)$ & $59(23)$ & $42(15)$ & $42(22)$ & $52(15)$ \\
\hline Owns rifles or shotguns & $62(78)$ & $59(23)$ & $56(20)$ & $69(36)$ & $57(17)$ \\
\hline
\end{tabular}

${ }^{*}$ Ethnic composition differs between experimental groups, $\chi^{2}=14.4, P=.006$.

${ }^{\dagger}$ Excluding 1 patient who reported owning 63 guns, mean number of guns is 2.4, range $1-10, \mathrm{SD}=2.1$.

changes in gun storage, with no significant differences between intervention groups. Eight participants made both safe and unsafe changes, 58 made safe changes only, 33 made no changes, and 28 made unsafe changes only.

\section{Predictors of Change in Gun Storage}

Demographic correlates of safe and unsafe changes included only ethnic group. Hispanic participants were significantly more likely than non-Hispanic whites to make safe changes ( $63 \%$ vs $42 \%, P=.026$ ) and significantly less likely to make unsafe changes in gun storage (16\% vs $40 \%, P=.003)$. Sex, age, children in the household, handgun ownership, rifle or shotgun ownership, and mean number of guns were unrelated to changes in gun storage.

The investigators conducted logistic regression analyses to examine the impact of the interventions

Table 2. Group Differences in Safe and Unsafe Changes Regarding Gun Storage.

\begin{tabular}{|c|c|c|c|c|c|}
\hline Change in Gun Storage & $\begin{array}{c}\text { Group 1 } \\
\text { Control Group } \\
(\mathrm{n}=39) \\
\%(\text { No. })\end{array}$ & $\begin{array}{c}\text { Group } 2 \\
\text { Verbal Counseling } \\
(\mathrm{n}=36) \\
\%(\text { No. })\end{array}$ & $\begin{array}{c}\text { Group } 3 \\
\text { Verbal }+ \text { Written } \\
\text { Counseling } \\
(\mathrm{n}=52) \\
\% \text { (No.) }\end{array}$ & $\begin{array}{l}\text { Patients } \\
\text { Completing } \\
\text { Project } \\
(\mathrm{n}=127) \\
\% \text { (No.) }\end{array}$ & $\begin{array}{l}\text { All Participants, } \\
\text { Including Lost-to- } \\
\text { Follow-up } \\
(\mathrm{n}=156) \\
\% \text { (No.) }\end{array}$ \\
\hline Made a safe change $^{\dagger}$ & $33(13)$ & $64(23)$ & $58(30)$ & $52(66)$ & $42(66)$ \\
\hline Made an unsafe ${ }^{\ddagger}$ change & $31(12)$ & $22(8)$ & $31(16)$ & $28(36)$ & $23(36)$ \\
\hline
\end{tabular}

*Safe change in gun storage is defined as reporting unlocked guns at enrollment and locked guns at follow-up, reporting loaded guns at enrollment and unloaded guns at follow-up, reporting access by children at enrollment but no access at follow-up, or at follow-up reporting moving guns to a safer place in the last 60 days.

${ }^{\dagger}$ Safe changes differ between experimental groups: $\chi^{2}=8.16, P=.017$.

${ }^{\ddagger}$ Unsafe change in gun storage is defined as reporting locked guns at enrollment and unlocked guns at follow-up, reporting unloaded guns at enrollment and loaded guns at follow-up, or reporting no access by children at enrollment but access at follow-up.

Note: Three-group comparison, $\chi^{2}=4.78, P=.092$; two-group comparison, $\chi^{2}=4.67, P=.031$. 
on safe and unsafe changes in gun storage while controlling for demographic and gun ownership influences. The following predictors were entered as a block: ethnic background, sex, age, number of children, number of guns, handgun ownership, and rifle ownership. Next, intervention or no intervention was entered as a dichotomous variable. After controlling for demographic and gun ownership variables, intervention group membership remained significantly related to safe changes $(P=$ $.012)$ in that participants in the intervention groups were three times more likely than controls to make a safe change (odds ratio $[\mathrm{OR}]=3.04 ; 95 \% \mathrm{CI}=$ $1.28,7.24)$. The entire model was significantly related to the safe change outcome $(P=.032$, Nagelkerke $\left.R^{2}=0.182\right)$. In contrast, unsafe changes were unrelated to intervention group membership. This model was significant $(P=.006$, Nagelkerke $R^{2}=0.240$ ), however, primarily because of the influence of ethnicity. Non-Hispanic whites were 4.7 times more likely to make unsafe changes in gun storage $(P=.002, \mathrm{OR}=4.71,95 \%$ $\mathrm{CI}=1.79$ to 12.37$)$.

\section{Intention-to-Treat Analysis}

Using the conservative assumption that the 29 participants lost to follow-up made no change in their gun storage habits, analyses of 156 participants showed that the results were still positive but the effect was reduced. Among those who did not report triple-safe storage at enrollment, $42 \%$ changed to triple-safe storage at follow-up: $25 \%$ in the control group, $44 \%$ in the verbal counseling group, and $51 \%$ in the counseling-plus-brochure group. A two-group comparison (control vs intervention groups combined) resulted in $\chi^{2}=4.44$ $(P=.035)$. An examination of safe changes provided similar findings. Twenty-nine percent of the control group made one or more safe changes compared with $46 \%$ and $49 \%$ in the intervention groups. A two-group chi-square comparison was significant $(P=.031)$. Finally, investigators repeated the logistic regression analysis to control for demographic and gun ownership variables and found that group membership was related to safe changes at the $P=.056$ level (compared with $P=$ .012 in the analysis of those who completed the study). In this analysis, intervention group participants were 2.2 times more likely than controls to make a safe change $(\mathrm{OR}=2.201,95 \% \mathrm{CI}=0.980$, 4.945). The entire model was moderately related to the safe change outcome $(P=.064)$. By contrast, unsafe changes were unrelated to experimental group membership.

\section{Participants' Comfort with Questions on Firearm Safety}

Finally, the investigators summarized participants' responses to the open-ended question: "Does it bother you to be asked about gun storage and safety at your doctor's office?" Seventy percent of these gun owners (88 participants) responded with an unqualified "no." Ten commented that it was a "good idea," that they were "glad the doctor was interested," or thought it was an "important issue." Nine percent (11 participants) were definitely bothered by the questions; most cited privacy issues. Four participants responded that it was "none of the doctor's business." The remaining 21\% (27 participants) reported being bothered "a little bit," or qualified their "no" response with comments, such as "I was surprised [by the question]," "I wondered why [I was being asked]," or they found it "curious," "strange," or "odd" that physicians would want to know about gun storage.

\section{Discussion}

We report a positive impact on patient's reported firearm storage habits after brief physician counseling. After a single encounter of verbal counseling or counseling plus a brochure, $64 \%$ and $58 \%$, respectively, of patients in these intervention groups who completed the study reported making one or more safe changes in gun storage. Participants in the intervention groups were far more likely to report triple-safe gun storage at a follow-up interview (unloaded, locked, inaccessible or unknown to children). Twelve percent of all those who completed the study reported getting rid of the gun(s) altogether.

Patients' attitudes regarding the subject matter were varied but, in general, positive. Most patients surveyed expressed neutrality or agreement with the appropriateness of the inquiry and counseling. Eleven patients maintained that firearm storage discussion was inappropriate in the clinical setting even after explanation of the motives.

There are limitations to our study. First, the sample size is small. Although the groups were fairly uniform, and the follow-up was greater than $80 \%$, a larger sample size in future studies will 
create more robust results. Second, there was a relatively disproportionate number of Hispanic patients compared with national figures. This unequal distribution in favor of Hispanics can be viewed as an advantageous starting point for future studies on Hispanics and firearm storage patterns, as firearm violence within the Hispanic community is understudied, ${ }^{17}$ and the Hispanic population is predicted to become the largest minority group in the United States by $2005 .^{18}$

Third, the percentage $(12.7 \%)$ of more than 1,200 patients screened who admitted to having a firearm in the home initially seems small compared with the national estimates of $40 \% .{ }^{19}$ A recent article on Hispanics and firearm violence, however, reported that only $11 \%$ of Hispanics owned guns. ${ }^{17,19}$ Considering our sample group was $76 \%$ Hispanic, the reported rate of household gun ownership might not be unreasonably low. Fourth, reporting bias could have been present, as the patients might have wanted to report a correct or acceptable answer to the surveyor. We note, however, that all three experimental groups had equal opportunity to fake an acceptable response for the physician who conducted the follow-up survey; yet the differences between control and intervention groups were dramatic.

Fifth, although the validity of self-reporting in gun ownership has been explored, ${ }^{20,21}$ it is unknown whether validity extends to self-reporting of firearm storage habits. Finally, when we take into account the 29 patients who were lost to follow-up and assume no changes in gun storage by these patients, our significant results are slightly less dramatic. Based on the experiences reported by the participants who did complete the study, it is quite likely that some of the participants lost to follow-up also made safe changes in gun storage. We believe that the truth lies somewhere in between. Either way, a positive impact is shown here.

After a review of mainstream literature, we found two studies that have published outcomes of safety counseling in primary care settings. Both studies were in pediatric settings and used similar counseling methods. One investigation was a nonrandomized study; ${ }^{22}$ the other was a randomized, controlled study. ${ }^{23}$ Neither study reported any significant differences with regard to gun storage patterns or ownership. Our setting is different in two ways: it is in a family practice setting and it has a high volume of Hispanic patients. It is possible that the physician-patient relationship in the family practice setting is different from the physicianpatient relationship in the pediatric setting, allowing a more direct impact on adults' health behaviors. It is also possible that interventions such as these are more effective in Hispanic communities. This study result does encourage further efforts in examining brief interventions for firearm safety.

Considering that counseling does take time, no matter how brief, the addition of even one-timeonly gun safety counseling to the long list of screening recommendations might be considered to be burdensome to some physicians. The US Preventive Services Task Force currently does not recognize sufficient evidence to recommend gun safety counseling. Intervention, however, is recommended by the American Academy of Family Physicians in its position paper on family violence, urging that "promoting reasonable and responsible control of firearms and other weapons" be among the physician activities to decrease family violence. ${ }^{24}$ Additionally, the American Medical Association encourages health professionals to "become educated in firearms injury prevention, including adolescent assault, homicide, and suicide," and "routinely screen for and counsel patients about firearms safety." ${ }^{10}$ Future studies regarding costbenefit ratio of these interventions seems logical. Determining a more exact benefit could result from long-term outcome evaluations following counseling.

The findings of this study suggest it is time to begin shifting the debate from gun ownership to gun safety and from "why counsel" to "how to counsel." Initiating the paradigm shift in attitudes and actions about firearm safety and influencing positively our patients' habits might be as efficient as brief office counseling.

The 2000-2001 Family Practice nurses, residents, and faculty of the Corpus Christi Family Practice Residency Program, Corpus Christi, Texas, participated in this study.

\section{References}

1. Gotsch KE, Annest JL, Mercy JA, Ryan GW. Surveillance for fatal and nonfatal firearm-related injuries - United States, 1993-1998. MMWR Morb Mortal Wkly Rep 2001;50:(SS-2).

2. Weil DS, Hemenway D. Loaded guns in the home. An analysis of a national random survey of gun owners. JAMA 1992;267:3033-7.

3. Injury mortality statistics. Atlanta, Ga: National 
Center for Injury Prevention and Control. Centers for Disease Control and Prevention, year.

4. Kellermann AL, Rivara FP, Somes G, et al. Suicide in the home in relation to gun ownership. N Engl J Med 1992;327:467-72.

5. Kellermann AL, Rivara FP, Rushforth NB, et al. Gun ownership as a risk factor for homicide in the home. N Engl J Med 1993;329:1084-91.

6. Parascandola M. Cigarettes and the US Public Health Service in the 1950s. Am J Public Health 2001;91:196-205.

7. CDC. Motor-vehicle safety. A 20th century public health achievement. MMWR Morb Mortal Wkly Rep 1999;48:369-74.

8. Firearm injury prevention. American College of Physicians. Ann Intern Med 1998;128:236-41.

9. American Academy of Pediatrics Committee on Injury and Poison Prevention. Firearm injuries affecting the pediatric population. Pediatrics 1992;89(4 Pt 2):788-90.

10. Connecting the dots to prevent youth violence: a training and outreach guide for physicians and other health professionals. Commission for the Prevention of Youth Violence. Chicago: American Medical Association: 2000.

11. A parent's guide to gun safety. Fairfax, Va: National Rifle Association Safety and Education Division, 1995.

12. Firearm safety depends on you. Wilton, Conn: Sporting Arms and Ammunition Manufacturer's Institute, 1997.

13. Price JH, Clause M, Everett SA. Patients' attitudes about the role of physicians in counseling about firearms. Patient Educ Couns 1995;25:163-70.

14. Shaughnessy AF, Cincotta JA, Adelman A. Family practice patients' attitudes toward firearm safety as a preventive medicine issue: a HARNET Study. Har- risburg Area Research Network. J Am Board Fam Pract 1999;12:354-9.

15. Barkin S, Duan N, Fink A, Brook RH, Gelberg L. The smoking gun: do clinicians follow guidelines on firearm safety counseling? Arch Pediatr Adolesc Med 1998;152:749-56.

16. Everett SA, Price JH, Bedell AW, Telljohann SK. Family practice physicians' firearm safety counseling beliefs and behaviors. J Community Health 1997;22: $313-24$.

17. Hispanics and firearms violence. Violence Policy Center, Washington DC. Available at: http://www. vpc.org/studies/hispintr.htm. Accessed 31 May 2001.

18. Census Facts for Hispanic Heritage Month. U.S. Census Bureau. United States Department of Commerce, 2000.

19. Cook PJ, Ludwig J. Guns in America: results of a comprehensive national survey on firearms ownership and use. Washington DC: Police Foundation, 1996:33.

20. Rafferty AP, Thrush JC, Smith PK, McGee HB. Validity of a household gun question in a telephone survey. Public Health Rep 1995;110:282-8.

21. Kellerman A, Rivara FP, Banton J, Reay D, Fligner CL. Validating survey responses to questions about gun ownership among owners of registered handguns. Am J Epidemiol 1990;131:1080-4.

22. Oatis PJ, Fenn Buderer NM, Cummings P, Fleitz R. Pediatric practice based evaluation of the Steps to Prevent Firearm Injury program. Inj Prev 1999;5: $48-52$.

23. Grossman DC, Cummings P, Koepsell TD, et al. Firearm safety counseling in primary care pediatrics: a randomized, controlled trial. Pediatrics 2000;106(1 Pt 1):22-6.

24. Family physicians against violence. AAFP position paper: family violence. Leawood, Kan: American Academy of Family Physicians, 2000. 